\title{
Kalp İskemi-Reperfüzyonunda Vitaminlerin Rolü
}

\author{
İlter DEMİRHAN*, Ergül BELGE KURUTAŞ***
}

\begin{abstract}
$\ddot{O} \mathbf{z}$
Günümüzde kardiyovasküler hastalıkların görülme insidansının artması bu alanda yapılan çalışmaları da beraberinde artırmıştır. Kalp hastalıkları içerisinde ölümlerin çoğunun miyokardiyal iskemiye bağlı olarak gerçekleştiği görülmektedir. Miyokardiyal iskemi-reperfüzyon hasarının etkili bir şekilde önlenmesi, tedavisinin nasıl sağlanacağı ve iskemi-reperfüzyon (I/R) hasarının altında yatan mekanizmaların incelenmesi, güncel araştırmaların en önemli noktasıdır. Vitaminler, insan vücudunda eser miktarlarda bulunmalarına rağmen çok önemli işlevlere sahiptir. Canlı bünyesinde vitamin eksikliği, dünyada ve ülkemizde yaygın sağlık sorunlarına neden olmaktadır. Son ylllarda vitaminlerin koruyucu etkisi ile kardiyovasküler sistem hastalıkları arasında bağlantı olduğunu gösteren çalışmalar bulunmaktadır. Antioksidan özellikli vitaminlerin kalbi koruyucu kardiyoprotektif mekanizmaları gösterilmiştir. Kalp I/R dokusunda hemoraji, myositolizis, ödem gelişmektedir. Kalpte meydana gelen I/R sonrasında oluşan nekrozun, hemorajinin, myositolizisin, ödem ve endotel disfonksiyonun vitaminler ile önlenebildiği çeşitli çalışmalar ile belirtilmektedir. Metabolom analizi ve elektron mikroskobu ile yapılan değerlendirmeler günümüzde vitaminlerin kalbi koruyucu rolünün olduğunu ispatlamaktadır. Vitaminler, antioksidan işlevi görerek serbest radikal hasarını azaltır ya da önler. Yeterince vitamin takviyesi alan kişilerin kalp hastalıklarına yakalanmadıkları veya hafif atlattıkları görülmektedir. Bu derlemede diyetle alınan vitaminler ile kardiyoprotektif etkileri ilişkilendirilmiş olup yapılan son çalışmalara göre dokularda bulunan biyobelirteçlerin değişimine göre sonuçlar özetlenmiştir.
\end{abstract}

\section{Derleme Makale (Review Article)}

Geliş / Received: 07.01.2021 \& Kabul / Accepted: 09.05.2021

DOI: https://doi.org/10.38079/igusabder.856218

${ }^{*}$ Dr. Öğr. Üyesi, Harran Üniversitesi, SHMYO, Elektrik-Otomasyon Bölümü, Şanlıurfa, Türkiye, E-posta: ilterdemirhan@harran.edu.tr ORCID https://orcid.org/oooo-0003-0054-7893

** Prof. Dr., Kahramanmaraş Sütçü İmam Üniversitesi, Tıp Fakültesi, Tibbi Biyokimya Bölümü, Kahramanmaraş, Türkiye, E-posta: ergulkurutas@gmail.com ORCID https://orcid.org/oooo$\underline{0002-6653-4801}$ 
Anahtar Kelimeler: İskemi-reperfüzyon, antioksidan, kardiyovasküler hastalıklar.

\title{
The Role of Vitamins in Heart Ischemia-Reperfusion
}

\begin{abstract}
Today, the increase in the incidence of cardiovascular diseases has increased the studies in this field. It is seen that most deaths among heart diseases occur due to myocardial ischemia. Effective prevention and treatment of myocardial ischemia-reperfusion injury and examination of the underlying mechanisms of ischemia-reperfusion (I/R) injury are the most important points of current research. Vitamins have very important functions, although they are found in trace amounts in the human body. Vitamin deficiencies in living beings cause widespread health problems in the world and in our country. In recent years, there are studies showing a link between the protective effect of vitamins and cardiovascular system diseases. Cardioprotective mechanisms of antioxidant vitamins have been shown. Hemorrhage, myocytolysis and edema develop in the heart I/R tissue. Various studies indicate that necrosis, hemorrhage, myocytolysis, edema and endothelial dysfunction occurring after ischemia-reperfusion in the heart can be prevented with vitamins. Evaluations made with metabolome analysis and electron microscope analysis prove that vitamins have a protective role in the heart today. Vitamins act as antioxidants, reducing or preventing free radical damage. It is observed that people who take enough vitamin supplements do not have heart disease or have a mild illness. In this review, dietary vitamins have been associated with their cardioprotective effects, and the results are summarized according to the changes in biomarkers in tissues according to the recent studies.
\end{abstract}

Keywords: Ischemia-reperfusion, antioxidant, cardiovascular diseases.

\section{Giriş}

Bir diradikal olan moleküler oksijen, indirgenmesi için elektron almak üzere redoks metal iyonlarının veya diğer radikallerin müdahalesine gereksinim duymaktadırlar. $\mathrm{Bu}$ şekilde üretilen oksijen radikalleri, oksijen toksisitesinden ve oksidatif stresten sorumludurlar. Reaktif oksijen türlerinin (ROS) oluşumunu ve faaliyetlerini önleyen doğal bileşiklere genel olarak antioksidan denilmektedir ${ }^{1}$. Antioksidanlar, zararlı her türlü eylemlere karşı insan vücudunu savunurlar. Antioksidanların bir kısmı vücutta sentezlenirken bir kısmı da dışarıdan diyetle alınmak zorundadır. Glutatyon ve ubikinol vücutta üretilirken askorbik asit, alfa-tokoferol, vitamin B gibi antioksidanlar dışarıdan alınmak zorundadır. Antioksidan özellikli maddeler genellikle bitkisel kökenlidir ve 
içeriğinde fazla miktarda fenolik bileşikler bulundururlar. Doğal olarak alınan düşük konsantrasyonlardaki bu ajanlar geniş kapsamlı biyolojik etkiler gösterirler. Antioksidan maddelerin fazla miktarlarda polifenolik bileşik içerdiği laboratuvar bulguları ile gösterilmiştir. Ancak klinik çalışmalar, her antioksidan ajanın patolojide hayati öneme sahip oksidatif stresi önlemediğini göstermektedir. Günümüzde, yapılan çalışmalar ile vitaminlerin kalp dokusu üzerinde iyileştirme özelliğinin olup olmadığ araştırılmaktadır. Eksojen antioksidan olan vitaminlerin koruyucu etkileri, oksidan hasarın belirteci olan proteinler, lipitler ve nükleik asitler üzerinde oluşturdukları etki ürünlerine göre değerlendirilmektedir².

\section{İskemi-Reperfüzyon}

İskemik kalp hastalığı, dünya üzerinde birçok ülkede ölümlerin majör nedeni olmakla birlikte Dünya Sağlık Örgütü (WHO) verilerine göre her yıl ortalama 4 milyon erkeğin ve 3,5 milyon kadının bu hastalığa bağlı olarak yaşamını kaybettiği bilinmektedir. 2012 yılı verilerine göre dünya genelinde ölümlerin \%46,2'si kalp hastalıklarına bağlı olarak meydana gelmektedir3. Kalp hastalıkları içinde en sık görülen iskemik kalp hastalıklarıdır4.

Organların yeterince kanlanmaması yani besin ve oksijen gibi yararlı maddelerin hücrelere ulaşamaması durumu iskemi olarak tanımlanır. Organları besleyen kan akım durumuna bağlı olarak hücrelerde birtakım anormalliklerin oluşumuna neden olur5. İskemi durumunda, aerobik metabolizmanın yavaşladığı, hücre içi enerji (ATP) sunumunun azaldığı gösterilmiştir. Bunların sonucunda hücre içi asidozların geliştiği ve kalsiyum iyonlarının birikimi ile ödem oluştuğu rapor edilmiştir. Reperfüzyon, iskemiye maruz kalan doku ya da organların yeniden kanlanması durumudur. İskemik dokunun canlılığını devam ettirebilmesi için reperfüzyon önemli bir süreçtir. Hücre hasarının önlenebilmesi için yeniden kan akımının olması gerekmektedir. Ancak yapılan bazı çalışmalar ile reperfüzyonun iskemiye bağlı olarak oluşan hasarı daha da artırdığı gözlenmiştir ${ }^{6}$. Yapılan çalışmalarda iskemi periyodunun 20 dakikayı aşan durumlarda meydana gelen reperfüzyonun hücresel nekroz veya miyokardiyal hasar oluşturduğu belirtilmiştir7.

Canlıların antioksidan dengesi, sağlıklı bir yaşam sürdürmeleri için büyük öneme sahiptir. Bunlar içerisinde vitaminler eksojen antioksidanlar grubunda yer alır. 
Vitaminlerin deneysel kalp iskemi reperfüzyon modellerinde antioksidan özelliğini kanıtlayan pek çok başarılı çalışma mevcuttur ${ }^{8,9}$.

\section{İskemi-Reperfüzyon Hasarının Kalp Üzerine Etkileri}

Kalpte, I/R hasarına bağlı olarak miyokardiyal bozulmalar, reperfüzyon aritmileri, miyositlerde nekroz, koroner endotelyal ve mikrovasküler disfonksiyon gözlenebilir ${ }^{10}$. Miyokardiyal sersemleme genellikle global iskemik ataklardan sonra gerçekleşse de kısa süreli iskemik ataklarda dahi oluşabildiği gözlenmiştir ${ }^{11}$. İskemik periyodu takip eden reperfüzyon dönemi ölümcül aritmilere öncülük edebilir. Oluşan aritmiler genellikle idioventrikülerdir ve en fazla ventriküler taşikardi ve fibrilasyon ile sonlanır ${ }^{12,13}$. Kalp hücrelerinde nekroz gelişimi I/R döneminde harekete geçen mekanizmaların ortak sonucudur. Bununla birlikte reperfüzyonun ilk dakikalarında gelişen nekrozun başlıca sebebi kalp hücrelerinde gelişen kontraktürdür ${ }^{14}$. I/R sonrası oluşan endotelyal bozulmalar, trombositlerin yol açtığı mikrovasküler tıkanıklık, ödem ve oksidatif hasar mikrovasküler disfonksiyona neden olur. Mikrovasküler disfonksiyonun oluştuğu kalp bölgelerinde reperfüzyon döneminde kan akımı kısıtlanır ve hipoperfüze alanlar gözlenir ${ }^{15}$.

\section{Oksidatif Stres}

Reaktif oksijen türleri (ROS), I/R hasarı esnasında miyokardda hızlı bir şekilde oluşmaktadır ve I/R hasarının başlıca sebebi olarak kabul edilmektedir ${ }^{16}$. Reperfüzyonun başlangıcında serbest radikal üretiminde artış ile mitokondriyal solunum hızlanır. Serbest radikal miktarındaki bu hızlı artış, serbest radikal yakalayıcı sistemlerin kapasitesini aşabilir ve hücresel fonksiyon kaybına yol açabilirler. Dokuların tüketmiş olduğu oksijenin büyük bir kısmı (\%95) aerobik metabolizma için kullanılırken, çok az bir kısmının (\%5) ROS’a çevrildiği tahmin edilmektedir. Oksijen vasıtasıyla üretilen en önemli reaktif türler arasında süperoksit $\left(\mathrm{O}_{2}{ }^{2-}\right)$, Hidrojen peroksit $\left(\mathrm{H}_{2} \mathrm{O}_{2}\right)$ ve hidroksil radikali $(\bullet \mathrm{OH})$ saylabilir. Bu radikaller membran hasarı, DNA yıkımı, protez aktivasyonu, lipid ve protein peroksidasyonu ve takiben nekroz ve apoptozis ile sonuçlanan hücre ölümüne yol açarlar ${ }^{17}$.

Memelilerde nitrik oksitin (NO) varlığı ilk kez 1916 yılında gösterilmiştir. Ardından 1985 yılında aktive olmuş makrofaj hücrelerinin NO salgıladığı görülmüştür. NO, normal fizyolojik koşullar ile birçok patofizyolojik durumlarda homeostazın sağlanmasında 
otokrin ya da parakrin olarak salgılanabilen hücresel ajandır ${ }^{18}$. NO; düz kas hücresi, endotel hücresi ve diğer birçok memeli hücresinde arjininden nitrik oksit sentaz (NOS) aracılığı ile sentez ediliri ${ }^{19}$. NO konsantrasyonundaki artışlar ya da azalmalar doku ve organ çalışmasını olumsuz yönde etkilemektedir ${ }^{20}$. NO normal fizyolojik canlı koşullarının gerçekleştirilebilmesi için gereklidir ${ }^{18}$. NO gastrointestinal sistemde bir takım hücreler üzerine etki ederek sekresyon, tonus ve motiliteyi sağlar. Ayrıca mukozal koruma, su ve elektrolitlerin absorbsiyonu gibi inflamasyonlarda etkili olduğu görülmüştür. Böbrek bozukluğu durumlarında da etkili bir ajan olduğu değerlendirilmektedir ${ }^{20}$. Rodentlerde streptozosin verilerek oluşturulan diyabette $\mathrm{Ca}^{+2} \mathbf{a}$ bağımlı NOS inhibitörleri verilmesi durumunda pankreasta makrofaj infiltrasyonunun azaldı̆̆ı ve hipergliseminin önlendiği düşünülmektedir ${ }^{21}$.

\section{İskemi-Reperfüzyon Hasarında Vitaminlerin Etkinliği}

İskemi-reperfüzyon (I/R) hasarının etkili bir şekilde önlenmesi ve tedavisinin nasıl sağlanacağı ile $\mathrm{I} / \mathrm{R}$ hasarı altında yatan mekanizmaların incelenmesi güncel araştırmaların en önemli konularındandır. Özellikle dışarıdan diyetle alınan vitaminlerin I/R önleyiciliği ile ilgili birçok çalışma literatürde mevcuttur ${ }^{16}$. Bununla birlikte kardiyak fonksiyon mekanizması altında yatan gerçekler vitaminleri etkisi üzerinden araştırılmaktadır. Genel olarak vitaminlerin kalp iskemi-reperfüzyonunda hasar önleyici olduğu söylenebilir. Birçok çalışmada vitaminlerin serbest radikal süpürücü olduğu belirtilmiştir²2 ${ }^{2}$ İnsan kalbinin fonksiyonlarını sağlıklı bir şekilde yerine getirebilmesi için enerjiye ihtiyaç duyar. Yuki ve arkadaşları yaptıkları çalışmada, kalpte enerji oluşumu için tiamin $\left(\mathrm{B}_{1}\right)$ vitamininin gerekli olduğunu fonksiyonel metabolom analizi ile ratlar üzerinde göstermişlerdir. Tiamin ile tedavi edilen kalpte mitokondri boyutunun tedavi edilmeyen kalpten daha büyük olduğunu göstermişlerdir. Bu durum daha büyük mitokondri ile enerjinin korunduğu sonucunu ortaya çıkarmıştır ${ }^{23}$. Jie ve arkadaşları rat kalbinde deneysel olarak yaptıkları I/R hasarında C vitamininin koruyucu rolü olduğunu, I/R hasarını önemli ölçüde azalttığını ve enerji (ATP) üretiminden sorumlu mitokondrinin fonksiyonel bütünlüğünü koruduğunu belirtmişlerdir²4. Benzer şekilde iskemi-reperfüzyonda D vitamininin de miyokardiyal hasarı önemli ölçüde azaltarak mitokondriyal fraksiyonları artırdığı çalışmalar da bulunmaktadır ${ }^{25}$. Maria ve arkadaşları I/R oluşturdukları kalpte mitokondriyal fraksiyonlar üzerine E vitaminin etkisini araştırdıkları çalışmalarında; E vitamininin kalpte enerji oluşumunu artırdığı 
sonucunu bildirmişlerdir ${ }^{26}$. Nicorandil ikili etki mekanizmasına sahip antianjinal bir ajandır. Yüksek oranda C vitamini içeren bir beta bloker olup kalp hastalarının kullanması ile yaşam kalitelerinin artacağını açıklayan birçok çalışma vardır. Gvishiani ve arkadaşlarının yaptıkları çalışmada kalpte enerji yolaklarının artırdığı gözlenmiştir²7. Jiaying ve arkadaşlarının kalpte I/R hasarına karşı Nicorandil bileşiğinin kalpte enerji metabolizması üzerine olumlu etkiler gösterdiğini ancak erken reperfüzyon süresinde nicorandil' in kalp I/R hasarına üzerine etkisiz olduğunu belirtmişlerdir ${ }^{28}$. Nicorandil üzerine Li-Ning ve arkadaşlarının yaptıkları çalışmada azalmış enerji içeriğinin Nicorandil uygulaması ile ortadan kaldırıldığı ve mitokondri bölgelerinin artırıldığı sonucuna varmışlardır29. Sonuç olarak literatür çalışmalarına bakıldığında vitaminlerin kalpte mitokondriyal hasarı azaltarak enerji korunumunda önemli bir rol oynadığı söylenebilir.

Programlı hücre ölümü apoptozis olarak tanımlanmaktadır. İskemi-reperfüzyon esnasında serbest radikallerin miktarında meydana gelen artışlar ve $\mathrm{Ca}^{+2}$ tuzlarının birikimi ile hücre apoptozise sürüklenmektedir. I/R hasarına bağlı hücre apoptozuna vitaminlerin etkisini araştıran çalışmalar görülmektedir. Naranjan ve arkadaşları $B_{5}$ ve $\mathrm{B}_{6}$ vitaminlerinin etkisini araştırdıkları çalışmada her ikisinin de $\mathrm{Ca}^{+2}$ iyonlarının aşırı yüklenmesini önlediği gösterilmiştir3o. Wang ve arkadaşlarının araştırmasında $\mathrm{B}_{6}$ vitamininin I/ $\mathrm{R}$ hasarlı kalpte $\mathrm{Ca}^{+2}$ iyon birikimini azalttığı belirtilmiştir31 ${ }^{1}$ Kalpte oluşan iskemi ile artan kalsiyum seviyesi, fosfolipazları ve proteazları aktive ederek radikal ve yağ asitleri oluşumunu artırır ve bu durum, hücre yaşamının sonlanması anlamına gelir32.

Kalpte, I/R hasarına bağlı olarak birtakım anormallikler görülmektedir. Miyokardiyal aritmileri, reperfüzyon aritmileri, miyositlerde nekroz, koroner endotelyal ve mikrovasküler disfonksiyon bunlardan bazılarıdır. Miyokardiyal bozukluk, iskemi reperfüzyona bağlı olarak geri dönüşsüz hasar olmamasına ve reperfüzyonun tam veya tamamına yakın bir şekilde sürmesine rağmen kalpte oluşan uzamış mekanik fonksiyon bozukluğu olarak tanımlanır33. Miyokardiyal sersemlemenin genellikle büyük iskemik ataklardan sonra gerçekleştiği belirtilmiştir ${ }^{11}$. Vitaminlerin miyokardiyal nekrozları azalttığını gösteren çalışmalar yapılmıştır. Pongkan ve arkadaşlarının yaptıkları çalışmada vitamin özelliği gösteren astaksantin, beta-kriptoksantin ve E vitaminlerinin etkileri araştırılmıştır. Miyokardiyal nekroz oluşumunun genel olarak \%36-57 oranında 
azaldığını gösterdikleri çalışmada beta-kriptoksantin verilen ratlarda bu azalma oranı \%70’e kadar çıkmıştır. Bu bakımdan beta kriptoksantin’in vitamin E ve astaksantine göre daha fazla kardiyoprotektif etki gösterdiği sonucuna varılmıştır34. Miyokardiyal nekroz önlenmesine yönelik farklı bir çalışmada; C vitamininin nekroz oluşumunu \%30’a kadar önlediği belirtilmiştir9. Wallert ve arkadaşları yaptıkları çalışmada E vitamininin miyokardiyal enfarktüs boyutunda azalmalara neden olduğu gösterilmiş ancak yüzde cinsinden oran verilmemiştir. Çalışmalarında denedikleri E vitamini formu olan $\alpha$ tokoferol'ün kalpte koruyucu etkilere sahip olduğu belirtilmiştir ${ }^{25}$. Kalp hücrelerinde nekroz oluşumu I/R esnasında bazı mekanizmalar tarafından uyarılır. Bununla beraber reperfüzyon döneminin başlangıcında meydana gelen nekrozun sebebinin kalp hücrelerinde meydana gelen kontraktür olduğu vurgulanmaktadır35.

Lipid peroksidasyonunda son ürün malondialdehittir (MDA) ve oksidatif hasarın düzeyini göstermede yaygın olarak kullanılmaktadır. Annapura ve arkadaşlarının yaptıkları çalışmada MDA düzeylerinde azalmalar gözlenmiştiri36. Benzer şekilde, Demirhan ve arkadaşlarının $B_{17}$ vitamini (Amigdalin) ile yaptıkları araştırma sonuçlarına göre MDA düşük seviyelerde gözlenmiştir ${ }^{37}$. Bir dokuda MDA seviyesinin artması serbest radikal seviyesinin arttığının göstergesi olarak kabul edilmektedir ${ }^{38}$. Yine benzer şekilde Liu ve arkadaşlarının ratlarda oluşturdukları kalp I/R modelinde C vitamini kompleksi guercetin'in MDA seviyelerinde azalmalara neden olduğu belirtilmiştir39. Son yllarda oksidatif hasarın biyobelirteci olarak MDA'nın oksidatif stres araştırmalarında sıklıkla kullanıldığg ve değerinin düşük bulunduğu görülmüştür36,37-39.

Süperoksit dismutaz (SOD), süperoksit radikalini hidrojen perokside dönüştüren dismutasyon reaksiyonunda etkili metalloprotein yapısında bir enzim olup antioksidan savunma kaynaklarından birisidir ve oksidatif stres çalışmalarında biyobelirteç olarak sıklıkla kullanılmaktadır. Mahmoudabady ve arkadaşlarının yaptıkları çalışmada A vitamini verdikleri rat grubunda SOD enzim düzeylerinde artış gözlemlemişlerdir ${ }^{40}$. Folik asit verilen rat grubunda SOD etkinliği artışı Ahmad ve arkadaşlarının kalp I/R modelinde gösterilmiştir ${ }^{41}$. Benzer şekilde SOD artışını destekleyen birçok çalışma olduğu görülmektedir ${ }^{42-44}$.

Katalaz (CAT) enzimi, SOD enzimi tarafından oluşturulan hidrojen peroksiti su ve oksijene çevirmekle görevlidir. CAT, vücutta doğal olarak oluşan bir metalloprotein bileşik olup in vivo olarak SOD ile birlikte etki eder. Rui-Qu Zhang ve arkadaşları kalp 
I/R modelinde B vitamini üzerine yaptıkları çalışmada tedavi grubunda CAT aktivitesi artışını rapor etmişlerdir45. Troxerutin, vitamin $\mathrm{P}_{4}$ olarak bilinir ve yaygın olarak kronik venöz yetmezliği durumlarında kullanılmaktadır. $P_{4}$ vitamininin kalp iskemireperfüzyonu üzerine yapılan çalışmada, miyokard enfarktüs boyutunun önemli ölçüde azaldığı ve CAT enzim aktivitesinin arttığını belirtilmiştir ${ }^{46}$. Literatür çalışmalarında SOD ve CAT’in kombine çalıştıkları gösterilmektedir. Tedavi uygulanan gruplarda CAT artışı literatür çalışmaları ile gösterilmiştir 46,47.

\section{Sonuç ve Öneriler}

İskemi ve ardından meydana gelen reperfüzyon dokularda çeşitli düzeylerde hasarlar oluşturmaktadır. Günümüzde birçok antioksidan ajan I/R hasarını yok etmek amacıyla araştırmacılar tarafından değerlendirilmektedir. En önemli antioksidan ajanlardan birisi de vitaminlerdir. Beslenme alışkanlıkları, stres, iş hayatı vb. olumsuzluklar kalp hastalıklarının görülme sıklı̆̆ını artırmıştır.

Vitaminlerin; superoksit radikali, hidroksil, peroksil ve alkoksil radikalleri ile etkileşime girerek antioksidan görev gördüğü ve lipid peroksidasyon zincir reaksiyonunu önleyebildiği saptanmıştır. Vitaminler antioksidan etkiyi değişik konsantrasyonlarda gösterir. Bazı vitaminler yüksek konsantrasyonlarda antioksidan etki gösterirken bazı vitaminlerin ise düşük konsantrasyonlarda antioksidan etki gösterdiği anlaşılmaktadır. Vitaminlerin kardiyak iskemide klinik kullanımı erken teşhis için de faydalı olacaktır. Ayrıca vitamin maliyetlerinin az olması kullanım avantajlarından bir diğeridir. Literatür çalışmalarına bakıldığında vitaminlerin; histopatolojik açıdan nekroz oluşumunu azalttığı, endotel disfonksiyon kaybını engellediği ve kardiyoprotektif etkiler gösterdiği görülmektedir. Vitaminlerin kardiyak ve kardiyak dışı hastalıklarda iskemi ile ilgisinin araştırılmasında klinik olarak yapılacak çalışmalara gereksinim vardır. Yapılacak çalışmaların biyokimyasal ve histopatolojik sonuçlarının paylaşılmasının yararlı olacağı inancindayı.

\section{KAYNAKLAR}

1. Ramasarma T. Dioxygen reduction, reduced oxygen species, oxygen toxicity and antioxidants. Indian Journal of Experimental Biology. 2016;54(11):688-99. 
2. Paradies G, Paradies V, Ruggiero FM, Petrosillo G. Mitochondrial bioenergetics and cardiolipin alterations in myocardial ischemia-reperfusion injury: implications for pharmacological cardioprotection. American Journal of Physiology Heart and Circulatory Physiology. 2018;315(5):1341-1352.

3. Andersen HR, Nielsen TT, Rasmussen K, et al. A comparison at coronary angioplasty with fibrinolytic therapy in acute myocardial infarction. The New England Journal of Medicine. 2018;349(8):733-742.

4. Ekmekçi H, Balcı Ö. Konjestif kalp yetmezliği ve B-tipi natriüretik peptid. Sendrom. 2002;(14)4:48-53.

5. Siemionow M, Arslan E. Ischemia/reperfusion injury: a review in relation to free tissue transfers. Microsurgery. 2004;24(6):468-475.

6. Collard CD, Gelman S. Pathophysiology, clinical manifestations, and prevention injury of ischemia-reperfusion. Anesthesiology. 2001;94(6):1133-1138.

7. Li C, Jackson RM. Reactive species mechanisms of cellular hypoxiareoxygeneration injury. American Journal of Physiology. 2002;282(2):227-241.

8. Silalahi J. Anticancer and health protective properties of citrus fruit components. Asia Pacific Journal of Clinical Nutrition. 2002;11(1):79-84.

9. Huseyin S, Guclu O, Yuksel V, Sezer G, Can N, Canbaz S. Avoiding liver injury with papaverine and ascorbic acid due to infrarenal cross-clamping: an experimental study. Brazilian Journal of Cardiovascular Surgery. 2017;3(3):197-201.

10. Kloner RA, Arimie RB, Kay GL, Cannom D, Matthews R, Bhandari A. Evidence for stunned myocardium in humans; a 2001 update. Coron Artery Disease. 2001;12(5):349-356.

11. Bolli R. Oxygen-derived free radicals and postischemic myocardial dysfunction. Journals of the American College of Cardiology. 1988;12(1):239-249.

12. Hearse DJ. Ischemia reperfusion, and the determinants of tissue injury. Cardiovascular Drugs and Therapy. 1990;12(4):767-776.

13. Manning AS, Hearse DJ. Reperfusion-induced arrhythmias: mechanisms and prevention. Journal of Molecular and Cellular Cardiology . 1984;16(6):497-518. 
14. Piper HM, Meuter K, Schafer C. Cellular mechanisms of ischemia-reperfusion injury. The Annals of Thoracic Surgery. 2003;75(2):644-648.

15. Murry CE, Jennings RB, Raimer KA. Preconditioning with ischemia: a delay of lethal cell injury in ischemic myocardium circulation. The Annals of Thoracic Surgery. 1986;74(5):1124-1136.

16. Lefer DJ, Granger DN. Oxidative stress and cardiac disease. The American Journal of Medicine. 2000;109(4):315-323.

17. Reiter RJ, Tan DX. Melatonin: a novel protective agent against oxidative injury of the ischemic-reperfused heart. Cardiovascular Research Journal. 2003;58(1):1019.

18. Kuyumcu A, Düzgün A, Özmen M, Besler HT. Travma ve enfeksiyonda nitrik oksidin rolü. Ulusal Travma ve Acil Cerrahi Dergisi. 2004;10(3):149-159.

19. Kaplan P, Hendrix M, Mubagwa K, Flameng W. Effect of ischemia and reperfusion on sarcoplasmic reticulum uptake. Circulation Research. 1992;71(3):1123-1130.

20. Atakişi O, Atakişi E, Atabay T, Uzun M. L-Arjinin ve N-Nitro -L-Arjinin metil esteri uygulamasının beyin, karaciğer, böbrek dokusu nitrik oksit ve malondialdehit düzeylerine etkisi. Kafkas Üniversitesi Veterinerlik Fakültesi Dergisi. 2009;16(1):71-75.

21. Atalık KE, Doğan N. Nitrik oksit ve fizyolojik etkileri. Genel Trp Dergisi. 1997;7(3):167-169.

22. Zaer AM, Marefati N, Atkin SL, Butler AE, Sahebkar A. The protective role of curcumin in myocardial ischemia-reperfusion injury. Journal of Cellular Physiology. 2018;231(1):214-222.

23. Yamada Y, Kusakari Y, Watanabe M, et al. Thiamine treatment preserves cardiac function against ischemia injury via maintaining mitochondrial size and ATP levels. Journal of Applied Physiology. 2020;130(1):26-35

24. Hao J, Li W, Du H, Zhao ZF, Liu F, Yang XC. Role of Vitamin C in cardioprotection of ischemia reperfusion injury by activation of mitochondrial KATP Channel. Chemical and Pharmaceutical Bulletin. 2016;64(6):548-557. 
25. Oian X, Zhu M, Oian W, Song J. Vitamin D attenuates myocardial ischemiareperfusion injury by inhibiting inflammation via suppressing the RhoA/ROCK/NF-kB pathway. Biotechnology and Applied Biochemistry. 2019;66(5):850-857.

26. Wallert M, Ziegler M, Wang X, et al. $\alpha$-Tocopherol preserves cardiac function by reducing oxidative stress and inflammation in ischemia/reperfusion injury. Redox Biology. 2019; 26:101292. doi: 10.1016/j.redox.2019.101292.

27. Gvishiani M, Gabunia L, Makharadze T, Gongadze N. Nicorandil efficacy in the treatment of ischemic heart disease. Georgian Medical News. 2018;280(3):152-155.

28. Li J, Xu X, Zhou X, Dai J, Ma L, Chen C. Cardiovascular events associated with nicorandil administration prior to primary percutaneous coronary intervention in patients with acute ST-segment elevated myocardial infarction: a systematic review and meta-analysis. Expert Opinion on Drug Safety. 2019;18(6):537-547.

29. Liang NL, Zhong X, Zhou Y, et al. Cardioprotective effect of nicorandil against myocardial injury following cardiac arrest in swine. American Journal of Emergency Medicine. 2017;35(8):1082-1089.

30. Dhalla NS, Takeda S, Elimban V. Mechanisms of the beneficial effects of vitamin B6 and pyridoxal 5-phosphate on cardiac performance in ischemic heart disease. Clinical Chemistry and Laboratory Medicine. 2013;1(3):535-543.

31. Wang X, Dakshinamurti K, Musat N, Dhalla NS. Pyridoxal 5'-phosphate is an ATPreceptor antagonist in freshly isolated rat cardiomyocytes. Journal of Molecular and Cellular Cardiology. 1999;31(5):1063-1072.

32. Birincioğlu M. İskemi-reperfüzyon aritmilerine ACE inhbitörleri, Glutatyon ve indometazinin etkileri [Yayımlanmamış Yüksek Lisans Tezi]. Malatya, Türkiye: İnönü Üniversitesi Sağlık Bilimleri Enstitüsü;1996.

33. Ertan T, Soran A, Kılıç M, et al. Kan malondialdehid ve total antioksidan seviyesinin önemi. Cerrahi Trp Bülteni. 2001;2(4):154-167.

34. Pongkan W, Takatori O, Yinhua N, et al. $\beta$-Cryptoxanthin exerts greater cardioprotective effects on cardiac ischemia-reperfusion injury than astaxanthin by 
attenuating mitochondrial dysfunction in mice. Molecular Nutrition and Food Research. 2017;61(10):1060-1077.

35. Liang S, Ping Z, Ge J. Coenzyme Q10 regulates antioxidative stress and autophagy in acute myocardial ischemia-reperfusion injury. Oxidative Medicine and Cellular Longevity. 2017;2017:9863181. doi: 10.1155/2017/9863181.

36. Annapurna A, Mudagal MP, Ansari A, Srinivasa RA. Cardioprotective activity of chalcones in ischemia/reperfusion-induced myocardial infarction in albino rats. Experimental and Clinical Cardiology. 2012;17(3):110-114.

37. Demirhan I, Kurutas EB, Bakaris S, Ozturk U, Oner E. Effects of B17 vitamin on sphingosine-1 phosphate and oxidative/nitrosative stress in the experimental model of heart ischemia/reperfusion. Advance Laboratory Medicine International. 2018;8(1):18-36.

38. Draper H, Hadley M. Malondialdehyde determination as index of lipid peroxidation. Methods in Enzymology. 1990;186(15):421- 31.

39. Liu H, Gua X, Shaoping L. Heart protective effects and mechanism of quercetin preconditioning on anti-myocardial ischemia reperfusion (IR) injuries in rats. The Journal of Gene Medicine. 2014;545(1):149-155.

40. Mahmoudabady M, Lashkari M, Niazmand S, Soukhtanloo M. Cardioprotective effects of Achillea wilhelmsii on the isolated rat heart in ischemia-reperfusion. Journal of Traditional and Complementary Medicine. 2017;7(4):501-507.

41. Ahmad S, Panda BP, Kohli K, Fahim M, Dubey K. Folic acid ameliorates celecoxib cardiotoxicity in a doxorubicin heart failure rat model. Pharmaceutical Biology. 2017;55(1):1295-1303.

42. Altuner D, Cetin N, Suleyman B, et al. Effect of thiamine pyrophosphate on ischemia-reperfusion induced oxidative damage in rat kidney. Indian Journal of Pharmacology. 2013;45(4):339-43.

43. Huang HY, Helzlsouer KJ, Appel LJ. The effects of vitamin C and vitamin E on oxidative DNA damage: results from a randomized controlled trial. Cancer Epidemiology Biomarkers and Prevention. 2000;9(7):647-52. 
44. Ravindran S, Murali J, Amirthalingam SK, Kurian GA. Vascular calcification abrogates the nicorandil mediated cardio-protection in ischemia reperfusion injury of rat heart. Vascular Pharmacology. 2017;89(2):31-38.

45. Zhang RQ, Dong YL, Tong X, Shu ZZ, Pan HJ, Wu X. Antioxidative effect of luteolin pretreatment on simulated ischemia/reperfusion injury in cardiomyocyte and perfused rat heart. Chinese Journal of Integrative Medicine. 2016;85(7):518-527.

46. Shu L, Zhang W, Huang C, Huang G, Su G. Troxerutin protects against myocardial ischemia/reperfusion injury via Pi3k/Akt pathway in rats. Cellular Physiology and Biochemistry. 2017;44(5):1939-1948.

47. Vinten J, Zhao J, Jiang R, et al. Preconditioning and postconditioning: innate cardioprotection from ischemia-reperfusion injury. Journal of Applied Physiology. 2007;103(4):1441-1448. 